\section{Prevalence of using pod-based vaping devices by brand among youth and young adults}

\section{BACKGROUND}

An estimated 10\%-44\% of youth and young adults have ever used JUUL, the leading e-cigarette brand in the USA, ${ }^{1}$ while $8 \%-9 \%$ reported past 30-day use of JUUL. ${ }^{2-5}$ Although there is growing attention on the prevalence of JUUL use, prevalence of using other brands of pod-based vaping devices is unknown. This information is important to assess whether newer brands are gaining popularity among young people and to complement sales data which do not track online purchases and sales through non-participating retailers or provide information about characteristics of users. ${ }^{1}$ This study assesses the prevalence of current use of JUUL, Suorin and Vuse across demographic and tobacco use characteristics among US youth and young adults.

\section{METHODS}

\section{Study population and procedure}

Data came from 2000 US youth and young adults recruited through the SSRS national online opt-in survey panel $^{6}$ : 15-17 years old (500 ever smokers, 500 never smokers) or 18-24 years old (500 who smoked within the past 30 days and had smoked $\geq 100$ lifetime cigarettes, 500 who did not smoke in the past 30 days or had smoked $<100$ lifetime cigarettes). Participants completed an online survey from December 2018 to January 2019.

\section{Measures}

Participants were asked if they have ever used JUUL, Suorin and Vuse. The question for Vuse referred to using the brand of e-cigarettes in general and was not limited to the pod-based sub-brand (ie, Vuse Alto). Response options were past 30-day use, ever use but not in the past 30 days, aware of the product but never used it, or not aware of the product. We computed a derived variable indicating past 30 -day use of any of the three brands (yes/no).

\section{Analyses}

We estimated the prevalence of using JUUL, Suorin and Vuse, stratified by youth and young adults and by individual characteristics. Data were weighted to reflect the distribution of the US population of these age groups by demographics and smoking status. ${ }^{78}$ A final adjustment was made so that the youth and young adult

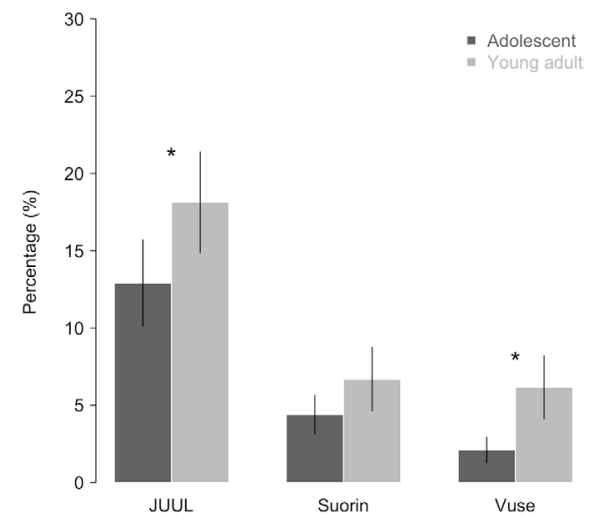

Figure 1 Weighted prevalence of current use (past 30 days) of JUUL, Suorin and Vuse among US youth $(\mathrm{N}=1000)$ and young adults $(\mathrm{N}=1000)$. * Statistically significant difference in prevalence between youth and young adults $(p<0.05)$.

groups are representative of the nationwide age distribution. ${ }^{9}$

\section{RESULTS}

Of the three brands, JUUL use was most prevalent among youth (12.9\%) and young adults (18.1\%), followed by Suorin (4.4\% and 6.7\%, respectively), and Vuse (2.1\% and 6.2\%, respectively; figure 1$)$. Overall, $15.0 \%$ of youth and $22.0 \%$ of young adults reported using any of these three brands in the past 30 days. Prevalence of using JUUL and Vuse were significantly higher among young adults than youth. Over three in four youth (76.4\%) and two in three young adults $(68.8 \%)$ are aware of JUUL. In comparison, less than half the youth are aware of Suorin (36.7\%) and Vuse (42.2\%). Among young adults, $37.0 \%$ are aware of Suorin and 51.9\% are aware of Vuse. Among youth, ever and past 30-day smokers and ever tried noncigarette tobacco products were associated with JUUL, Suorin and Vuse use (table 1). Additionally, non-Hispanic white youth were more likely to use JUUL (compared with other races/ethnicities), while youth in 11 th or 12 th grades were more likely to use Suorin (compared with 10th grade or below). Among young adults, being male and ever tried non-cigarette tobacco products was associated with JUUL, Suorin and Vuse use. Furthermore, ever and past 30-day smoking was associated with JUUL use, while past 30-day smoking was associated with Suorin use.

\section{DISCUSSION}

The findings of higher rates of awareness and current use of JUUL compared with Suorin and Vuse e-cigarettes are aligned with JUUL as the market leader, ${ }^{1}$ being the most popular device among highschool youth who ever used e-cigarettes, ${ }^{10}$ increased media and news coverage, promotion on social media platforms, online engagement about JUUL, ${ }^{11} 12$ and sharing about JUUL via word-of-mouth in recent years. ${ }^{13}$ The worrisome trend of social normalisation of e-cigarette use among young people could potentially renormalise combustible cigarette use due to a fourfold increased odds of initiating smoking among e-cigarette users. ${ }^{14}$ The high nicotine content of newer podbased vaping devices may further increase the risks of nicotine addiction and initiating smoking. ${ }^{15}$ Efforts to restrict access of pod-based devices, ban flavours that appeal to young people, and countermarketing campaigns on the addictiveness of vaping are needed to stem this growing trend. Surveillance of not just the use of JUUL but also other popular pod-based brands (eg, Suorin, Bo and PHIX) ${ }^{16}$ is recommended to more accurately assess the prevalence of vaping among young people.

Limitations of this study include a nonprobability-based sample, although we recruited a large sample nationally and weighted analyses to match the US population in this age group. We were not able to assess prevalence of using all available brands of pod-based vaping devices. Current use was based on self-reported measures which are subject to recall bias.

In sum, this study contributes new evidence on the prevalence of using JUUL, Suorin and Vuse among a national sample of US youth and young adults to inform future surveillance and intervention efforts.

\section{Andy S L Tan $\odot{ }^{1,2}$ Samir S Soneji, ${ }^{3}$ Kelvin Choi $\odot{ }^{4}{ }^{4}$ Meghan B Moran ${ }^{5}$}

${ }^{1}$ Department of Medical Oncology, Division of Population Sciences, Center for Community-Based Research, Dana-Farber Cancer Institute, Boston, Massachusetts, USA

${ }^{2}$ Department of Social and Behavioral Sciences, Harvard T.H. Chan School of Public Health, Boston, Massachusetts, USA

${ }^{3}$ The Dartmouth Institute for Health Policy \& Clinical Practice, Geisel School of Medicine at Dartmouth University, Lebanon, New Hampshire, USA

${ }^{4}$ Division of Intramural Research, National Institute on Minority Health and Health Disparities, Bethesda, Maryland, USA

${ }^{5}$ Department of Health, Behavior \& Society, Johns Hopkins Bloomberg School of Public Health, Baltimore, Maryland, USA

Correspondence to Dr Andy S L Tan, Department of Medical Oncology, Division of Population Sciences, Center for Community-Based Research, Dana-Farber Cancer Institute, Boston, Massachusetts 02215, USA; andy_tan@dfci.harvard.edu

Contributors MM designed and implemented the study. MM, ASLT, SS and KC generated the survey 
Table 1 Participant characteristics and weighted prevalence of past 30-day use JUUL, Vuse, and Suorin by characteristics of youth and young adults

\begin{tabular}{|c|c|c|c|c|c|c|c|c|}
\hline \multirow[b]{2}{*}{ Participant characteristics } & \multicolumn{4}{|c|}{ Youth $(\mathrm{N}=1000)$} & \multicolumn{4}{|c|}{ Young adult $(\mathrm{N}=1000)$} \\
\hline & $\begin{array}{l}\mathrm{N}(\%) \text { or } \\
\text { mean (SD) }\end{array}$ & JUUL use (\%) & Suorin use (\%) & Vuse use (\%) & $\begin{array}{l}\mathrm{N}(\%) \text { or } \\
\text { mean (SD) }\end{array}$ & JUUL use (\%) & Suorin use (\%) & Vuse use (\%) \\
\hline Age & $16.3(0.7)$ & - & - & - & $20.9(2.0)$ & - & - & - \\
\hline \multicolumn{9}{|l|}{ Gender } \\
\hline Male & $397(39.7)$ & 13.3 & 4.6 & 1.9 & $436(43.6)$ & $23.3 \S$ & $9.3^{\S}$ & $9.2^{\S}$ \\
\hline Female & $544(54.4)$ & 13.2 & 4.3 & 1.8 & $540(54.0)$ & $12.8^{\S}$ & $4.2^{\S}$ & $3.3^{\S}$ \\
\hline $\begin{array}{l}\text { Transgender or other gender } \\
\text { identities }\end{array}$ & $57(5.7)$ & 8.2 & 4.1 & 5.8 & $24(2.4)$ & $19.2^{\S}$ & $3.6^{\S}$ & $1.9^{\S}$ \\
\hline Missing & $2(0.2)$ & - & - & - & $0(0.0)$ & - & - & - \\
\hline \multicolumn{9}{|l|}{ Sexual orientation ${ }^{*}$} \\
\hline Heterosexual & - & - & - & - & $795(79.5)$ & 17.4 & 7.2 & 6.6 \\
\hline Lesbian or gay & - & - & - & - & $40(4.0)$ & 20.9 & 4.7 & 2.1 \\
\hline Bisexual & - & - & - & - & $133(13.3)$ & 24.7 & 4.0 & 2.6 \\
\hline Something else & - & - & - & - & $14(1.4)$ & 10.7 & 0.0 & 0.0 \\
\hline Missing & - & - & - & - & $18(1.8)$ & - & - & - \\
\hline \multicolumn{9}{|l|}{ Race/ethnicity } \\
\hline Non-Hispanic white & $448(44.8)$ & $16.1^{\S}$ & 5.6 & 1.6 & $490(49.0)$ & 19.8 & 7.2 & 5.6 \\
\hline Non-Hispanic black & $179(17.9)$ & $6.3^{\S}$ & 2.9 & 2.2 & $184(18.4)$ & 11.7 & 7.1 & 7.2 \\
\hline Hispanic & $215(21.5)$ & $12.1^{\S}$ & 2.3 & 3.4 & $219(21.9)$ & 19.9 & 4.7 & 6.8 \\
\hline Non-Hispanic other races & $158(15.8)$ & $7.1^{\S}$ & 4.5 & 1.8 & $107(10.7)$ & 14.8 & 7.9 & 6.3 \\
\hline \multicolumn{9}{|l|}{ Highest grade of school completion } \\
\hline 9th grade or below & $191(19.1)$ & 9.5 & $2.2^{\S}$ & 1.1 & $24(2.4)$ & 16.4 & 9.1 & 4.7 \\
\hline 10th grade & $286(28.6)$ & 13.4 & $3.2^{\S}$ & 1.7 & $18(1.8)$ & 0.0 & 0.0 & 12.7 \\
\hline 11 th grade & $331(33.1)$ & 13.2 & $7.0^{\S}$ & 2.4 & $34(3.4)$ & 10.1 & 5.9 & 2.3 \\
\hline $\begin{array}{l}\text { 12th grade/high school degree/ } \\
\text { General Education Development } \\
\text { (GED) }\end{array}$ & $169(16.9)$ & 17.2 & $6.3^{\S}$ & 4.6 & $377(37.7)$ & 17.9 & 8.4 & 7.3 \\
\hline Some college, but no degree & $0(0.0)$ & - & - & - & $303(30.3)$ & 21.4 & 7.3 & 5.5 \\
\hline Associate degree & $0(0.0)$ & - & - & - & $94(9.4)$ & 15.2 & 6.3 & 6.3 \\
\hline Bachelor's degree and above & $0(0.0)$ & - & - & - & $141(14.1)$ & 20.9 & 2.0 & 4.6 \\
\hline Missing & $23(2.3)$ & - & - & - & $9(0.9)$ & - & - & - \\
\hline \multicolumn{9}{|l|}{ Cigarette smoking status } \\
\hline Never Smoker & $500(50.0)$ & $6.7^{\S}$ & $1.9^{\S}$ & $1.0^{5}$ & $292(29.2)$ & $7.8^{5}$ & $5.1^{\S}$ & 5.1 \\
\hline Ever but not past 30-day Smoker & $379(37.9)$ & $28.8^{\S}$ & $9.7^{\S}$ & $4.8^{\S}$ & $159(15.9)$ & $27.0^{\S}$ & $5.1^{\S}$ & 4.8 \\
\hline Past 30-day Smoker ${ }^{\dagger}$ & $121(12.1)$ & $50.3^{\S}$ & $22.0^{\S}$ & $9.0^{5}$ & $549(54.9)$ & $30.0^{5}$ & $12.5^{\S}$ & 10.2 \\
\hline \multicolumn{9}{|l|}{ Ever tried other tobacco products ${ }^{\ddagger}$} \\
\hline No & $644(64.4)$ & $8.3^{\S}$ & $3.1^{\S}$ & $1.4^{\S}$ & $363(36.3)$ & $10.9^{\S}$ & $4.9^{\S}$ & $2.0^{\S}$ \\
\hline Yes & $343(34.3)$ & $40.6^{\S}$ & $12.4^{\S}$ & $6.2^{\S}$ & $628(62.8)$ & $32.6^{\S}$ & $10.3^{\S}$ & $14.4^{\S}$ \\
\hline Missing & $13(1.3)$ & - & - & - & $9(0.9)$ & - & - & - \\
\hline
\end{tabular}

*Youth participants were not asked the sexual orientation question.

†This category included all participants who smoked in the past 30 days, including those who may not have smoked 100 lifetime cigarettes.

$\ddagger$ Other tobacco products include hookah or waterpipe, cigars, cigarillos, or little cigars, smokeless (chew, snuff, or dip), roll-your-own, pipe, snus, dissolvables, and bidi.

$\S \chi^{2}$ tests significant at $p<0.05$.

questions used for the study collectively. MM, SS and ASLT performed the analysis. ASLT and SS wrote the manuscript. All authors contributed to revising the manuscript.

Funding Data collection for this study was supported by the National Institute on Drug Abuse and Food and Drug Administration Center for Tobacco Products (K01DA037903-S1). MM's effort were supported by the National Institute on Drug Abuse and Food and Drug Administration Center for Tobacco Products (K01DA037903). KC's effort is supported by the National Institute on Minority Health and Health Disparities Division of Intramural Research. Funding sources did not have any role in the study design; collection, analysis and interpretation of data; writing the report; the decision to submit the report for publication. The content is solely the responsibility of the authors and does not necessarily represent the official views of the US Government, the Department of Health and Human Services, the Food and Drug Administration, or the National Institutes of Health.

Competing interests $\mathrm{MM}$ is serving as an expert witness for the prosecutor (Public Health Advocacy Institute) in litigation in which RJ Reynolds Tobacco Company was the defendant.

Patient consent for publication Not required.

Ethics approval and informed consent The Johns Hopkins University Bloomberg School of Public Health's Institutional Review Board reviewed and approved the study protocol (IRB00008763). Youth and young adult participants read an information sheet on the first page of the survey and clicked a button indicating they agreed to take the survey. We had a waiver of parental consent.
Provenance and peer review Not commissioned; externally peer reviewed.

To cite Tan ASL, Soneji SS, Choi K, et al. Tob Control 2020;29:461-463.

Received 19 March 2019

Revised 16 May 2019

Accepted 17 May 2019

Published Online First 7 June 2019

Tob Control 2020;29:461-463.

doi:10.1136/tobaccocontrol-2019-055064 
ORCID iDs

Andy S L Tan http://orcid.org/0000-0001-6459-6171

Kelvin Choi http://orcid.org/0000-0002-6753-2883

\section{REFERENCES}

1 Huang J, Duan Z, Kwok J, et al. Vaping versus JUULing: how the extraordinary growth and marketing of JUUL transformed the US retail e-cigarette market. Tob Control 2019;28:146-51.

2 Willett JG, Bennett M, Hair EC, et al. Recognition, use and perceptions of JUUL among youth and young adults. Tob Control 2019;28:115-6.

3 Vallone DM, Bennett $\mathrm{M}$, Xiao $\mathrm{H}$, et al. Prevalence and correlates of JUUL use among a national sample of youth and young adults. Tob Control 2019;28:603-9.

4 McKelvey K, Baiocchi M, Halpern-Felsher B. Adolescents' and young adults' use and perceptions of Pod-Based electronic cigarettes. JAMA Netw Open 2018;1:e183535

5 Morean ME, Camenga DR, Bold KW, et al. Querying about the use of specific e-cigarette devices may enhance accurate measurement of e-cigarette prevalence rates among high school students. Nicotine Tob Res Off J Soc Res Nicotine Tob Published Online First: 5 November 2018.

6 SSRS Online Solutions. Online solutions. SSRs. Available: https://ssrs.com/online-solutions/ [Accessed 15 Mar 2019].

7 CDC - 2016 BRFSS Survey Data and Documentation, 2019. Available: https://www.cdc.gov/brfss/annual_ data/annual_2016.html [Accessed 15 Mar 2019].

8 CDC's Office on Smoking and Health. National Youth tobacco Survey (NYTS). Smok. Tob. Use, 2019. Available: http://www.cdc.gov/tobacco/data_statistics/ surveys/nyts/ [Accessed 15 Mar 2019]

9 Flood S, King M, Rodgers R. 2018. Integrated public use Microdata series, current population survey: version 6.0.

10 Krishnan-Sarin S, Jackson A, Morean M, et al. E-cigarette devices used by high-school youth. Drug Alcohol Depend 2019;194:395-400.
11 Chu K-H, Colditz JB, Primack BA, et al. JUUL: spreading Online and Offline. J Adolesc Health 2018;63:582-6.

12 Malik A, Li Y, Karbasian H, et al. Live, love, Juul: User and content analysis of Twitter posts about Juul. Am J Health Behav 2019:43:326-36.

13 Moran MB, Chen-Sankey JC, Tan AS, et al. Sources of awareness of JUUL e-cigarettes in 2 surveys of adults in the United States. Am J Health Behav 2019:43:279-86.

14 Soneji S, Barrington-Trimis JL, Wills TA, et al. Association between initial use of E-cigarettes and subsequent cigarette smoking among adolescents and young adults: a systematic review and meta-analysis. JAMA Pediatr 2017;171:788-97.

15 Barrington-Trimis JL, Leventhal AM. Adolescents' Use of "Pod Mod" E-Cigarettes - Urgent Concerns. N Engl J Med 2018;379:1099-102.

16 Ramamurthi D, Chau C, Jackler RK. JUUL and other stealth vaporisers: hiding the habit from parents and teachers. Tob Control 2019;28:610-6. 